conscience and investigate diligently whether it agrees with the laws of that allpower of which we are a small part and through which alone we exist.

Professor Jodl praises very highly the French institution of a so-called purely moral instruction in the public schools. Father H. Gruber, however, points out some serious shortcomings in this system of moral education, resuling from a lack of principle. (See Stimmen aus Maria-Laach, Freiburg i. B., I892, No. 4.)

It is apparent that moral commands cannot be based upon purely subjective notions or ideals, they must be based upon some objective authority which is a power that enforces obedience. Such a power exists. It is the world in which we live. It is that All-being of which we are a part. And that feature of nature which enforces that conduct which we call moral is named God in the terminology of religious language.

A consideration like this points out the way to a reconciliation between science and religion. There is a truth in the old religions, and this truth need only be purified from the errors that cluster about it, hiding its grandeur, beauty, and importance. Let the church and its authorities recognise science and the principle of free investigation; let them be ready to accept the scientific methods of research ; let them be willing to accept truth as it can be proved by arguments and verified by experience as well as by experiments; and we need no longer worry about dogmatism and the narrowness of their sectarian doctrines. All these accidental features of religion will, then, pass away, and we shall have a religion which the scientist and the philosopher can embrace.

This is what we call the Religion of Science; and the Religion of Science is bound to be the religion of the future. The Religion of Science will not abolish the religions of the past, but it will develop them, broaden them, perfect them, into the cosmical religion of humanitarianism.

To teach an ethics that either has no sanction, or whose sanction is built upon the diverging opinions of individuals, will not do. Ethics must be based upon the sanction of some objective authority, and the recognition of an objective authority, of a power which enforces a certain kind of conduct, being religion, we say that no ethics can be without a religious basis.

The problem at present is not how to teach irreligious ethics-all such attempts are failures at the start; but to change the mythology of the old religions into a clear, scientific conception of the natural conditions which demand of man that he should observe those rules which we are wont to call moral.

P. C.

\title{
THE FUTURE POSITION OF LOGICAL THEORY.
}

In last October's number of 7 he Monist, Professor John Dewey gives a sketch of what in his view is "the present position of logical theory." According to this the basis of the position seems to be that "the only possible thought is the reflection of the significance of fact," and that therefore logic, which is the science of the laws of thought, rests in reality on an objective basis. He supports Hegel in de- 
nying " the existence of any faculty of thought which is other than the expression of fact itself." Now it is doubtless the case that this is the position at present taken up by a large number of logicians, but as this position seems to me to be fundamentally erroneous I should like to put before your readers what I hope will be "the future position of logical theory." I have elsewhere worked out in some detail a theory of reasoning which differs from that commonly accepted chiefly in this, that it recognises not two, but three kinds of reasoning, which I call Objective, Subjective, and Symbolic. Reasoning is commonly divided into two branches, denoted by various pairs of terms, such as Objective and Subjective, Inductive and Deductive, Empirical and Formal. The lines of division indicated by these various pairs of terms are not quite identical; but they none of them indicate what seems to me the most important distinction of all, namely that between real, and symbolic argument. There do's exist (I will not say a "faculty of thought," but) a method of argument which "is other than the expression of fact itself," whether of objective or of subjective fact. The term "formal reasoning" is indeed of ten used to denote this kind of argument, but this is a bad name to give it, since it seems to imply, and frequently is held to imply, that it deals with the forms of objective or subjective facts, whereas in reality it deals only with symbols, which are arbitrarily defined, and which do not necessarily correspond to any things whatever, whether objective or subjective. That this kind of argument not only exists, but flourishes is evident as soon as it is grasped that pure mathematics is nothing but a branch of symbolic logic. It may be that there exists somewhere a fact of which any conceivable mathematical formula might be regarded as the reflexion, but it must surely be evident that it was not to the reflexion of such facts that mathematical formulæ in general owe their existence or validity. It may perhaps be true " that fact, reality is significant," and even that thoughts are themselves such significant realities, but it is the thoughts that are given to us first, or rather sensations which are the elements of thoughts, and we can only infer the realities from them, and not rice i'ersa.

The essence of my theory of logic may be briefly stated thus. The meaning of a logical term contains two parts, its denotation and its connotation. Either of these parts may be laid down arbitrarily as its definition, leaving the other part which I call its import to be found out by experience. To understand both parts of the meaning of any term is therefore to possess real knowledge. Pure symbolic reasoning deals only with the definitions of terms, and is not therefore founded on real knowledge, nor can it alone ever lead to real knowledge. Thus if in any proposition the definitions of the terms are deducible from one another, the proposition may be proved symbolically and is what I call a truism: it gives no real information. But if the definitions of the terms are independent of each other, and yet not inconsistent, the proposition can only be intended to assert the identity of the imports of the terms; it therefore ascribes import to the terms and gives real information, whether true or false. If any terms in a symbolic argument are however 
known to have real import, it may be ascribed to them in real propositions, and any conclusions of the argument which contain only such terms will ipso ficto be made to yield real information, which may be new in the sense that it was not before recognised, though it was of course implied in the real assertion or assertions which ascribed import to the terms of the symbolic argument.

It is in this way possible to separate any science into two branches, one of which consists purely of symbolic argument founded on definitions alone, while the other may be expressed in a series of propositions, the definitions of whose terms are independent of each other, and which ascribe real import (whether objective or subjective) to the terms of the symbolic science, or some of them.

This is as far as pure logic can go. The question how the truth of any real propositions comes to be known is not, in my opinion, any part of logical theory, but belongs to metaphysics. However that is no reason for not discussing it here, especially as it is the chief question discussed in Professor Dewey's paper.

"Truth" means some sort of consistency in a proposition. We may compare a symbolic argument to a game with counters, the rules of which are laid down arbitrarily, and to say that a given conclusion of such an argument is true only means that the game has been "played fair." But the truth of a real proposition does not depend on any arbitrary rules. It expresses a consistency between two real facts, either that two named groups of things possess certain common attributes, or that certain of the things possessing named groups of attributes are identical. The essential element of all real knowledge is then a connecting link between a thing and an attribute, such as is afforded by a well-understood word.

Now the only "things" which we can apprehend directly are our subjective sensations and conceptions. We can compare two or more sensations or conceptions, and recognise in them common attributes. Thus I can say of my own knowledge that the sensations I denote by "the taste of sugar" and "the taste of lead acetate" have a common attribute, which I call "sweetness." This is a real assertion, for its truth is not deducible from the definitions of its terms, and yet $I$ know, by direct apprehension, that it is true. But it is only a subjective truth. The corresponding objective assertion would be sugar and acetate of lead both produce, when tasted, the sensation of sweetness. And I have no direct apprehension of this fact. That the tastes referred to in the former proposition were produced by objective things denoted by the terms sugar and acetate of lead, can only be inferred by the process called induction, which can never lead to a positive or necessary truth.

Thus we may from a pure symbolic science proceed one step further, to a subjective science, by the aid of direct apprehension, and the results of such a subjective science may in certain cases attain the position of absolute, or necessary truths. But on the other hand, all objective sciences must rest on induction. Now the true nature of induction is, I am persuaded, commonly misapprehended, because it is not realised sufficiently clearly that the prime data of induction are not them- 
selves objective, but subjective facts. An "objective fact" is really only an hypothesis, postulated to account for certain of our subjective sensations. The only justification for making such an hypothesis is that it actually does explain certain sensations, and the measure of its probability (for we can never assert it as a necessary certainty) is the number and complexity of the sensations which it accounts for. The first of all such objective hypotheses is that we have an objective environment to whose action our sensations, or some of them. are due. This suggests at once a more general hypothesis, commonly known as the law of causation namely that the conditions obtaining in the objective universe at any one moment are the effective causes of those obtaining at the next, and so at any subsequent moment. These two hypotheses, together with certain subsidiary ones, do suffice to account for an enormous number, if not all, of our sensations, and so we are justified in entertaining them. But to leave out the notion of effectice causation, and to substitute a mere rule of sequence, is to remove the only justification we have for assuming the hypothesis of causation at all. It is perhaps conceivable that the hypothesis may be false, that our sensations are not "caused by" an objective environment but if so what reason remains for believing in that environment at all? I can never know anything whatever about an objective universe, unless some of my sensations about which alone I know anything directly, are caused by that universe. It is perhaps thinkable that there should be an objective universe in which events occur which in no sense cause my subjective sensations, but to which those sensa. tions nevertheless happen to correspond; but if this is so the sensations afford me no ground whatever for believing in the occurrence of the events, or the objectivity of the universe.

Well then, the essence of induction is the assumption of an hypothesis to account for observed facts-first of all of directly observed sensations, and then of facts assumed to be objective in virtue of the primary hypothesis. That this account of induction is the true one is I think particularly enforced by the consideration of those cases to which at first sight it does not seem to apply. A common example of induction is afforded by our belief that the sun will rise to-morrow. That it has risen every morning for the last four thousand years or more is no reason whatever for believing that it will rise to-morrow, unless it is held to point to some explanatory hypothesis. Such an hypothesis has actually been framed by astronomers, and no one would now pretend to found his belief in the sun's rising to-morrow on the mere fact that it has often risen before, but would go on to explain that it must rise unless the earth were to stop revolving, etc. If at Monte Carlo the red turned up ten times running, would that be any reason for expecting it to turn up again, the eleventh time? No, it would not unless the succession of reds seemed to point to some explanatory hypothesis, such as a defect in the roulette. Again, the fact that in the last fifty years the death rate in London has been about twenty-eight per thousand would be no reason for believing that it will be about that figure this year 
except on the assumption that the constancy of the death rate indicated certain constant causes, which we have no reason to believe have been altered this year.

Having once assumed that our environment is objective, and as a corollary the hypothesis of causation, the whole of physical science follows, step by step. Subsidiary hypotheses are introduced at each stage and justified by the way they account for observed results. To show how a single hypothesis is capable of explaining a large number of observed results, the full meaning of the hypothesis is elucidated by symbolic reasoning. By such reasoning it is for example shown that the same hypothesis, of universal gravitation, is capable of accounting, not only for the movements of the stars, but for the tides, the flow of rivers, the falling of unsupported bodies, the rising of baloons, the movements of the balance in Cavendish's experiment, and so on. That such wide extensions of an hypothesis are possible tends greatly to confirm, not only the hypothesis itself, but the fundamental hypotheses of objectivity and causation also. But it does not prove either the one or the others. We cannot know anything about the objective universe with absolute certainty, but we may reasonably believe a certain hypothesis about it with any degree of conviction we think suitable; that is we may (and of course we actually do) act on all occasions as if we knew absolutely that they were true.

We may then believe, and I for one do believe, not only in the objectivity of the universe, but that even my own subjective sensations are mere bye-products of that universe, I beliez'e that objective facts are, if I may so express it, more real than subjective sensations; that in fact the objective universe might have existed, and might exist again without any subjective element in it anywhere. But I cannot Fnow this, it is with me a matter of faith. Thus I cannot agree with Hegel, that "all possible thought is the reflexion of the significance of fact" (except perhaps in the sense that thought is the reflexion of the significance of certain changes in the grey matter of the brain) for this would seem to imply that stupid or contradictory though ts reflected stupid or contradictory significance in certain facts. But I believe that men of science are gradually evolving a system of thought which will more and more faithfully reflect the significance of fact, and that thus science is actually building up truth. But all science must begin with, and be founded upon. subjective knowledge, and therefore any theory of positivism contradicts itself for it must be founded on faith. Science is thus founded on faith, faith in things not directly apprehended, just as truly as religion is. It is only because we unconsciously acquire this faith in our infancy, and that it is in most cases amply justified by subsequent experience, that we do not even recognise the fact that it is faith, in exactly the same sense that belief in God is. But just as men have sometimes lost their faith in God, so it may happen to a man to loose his faith in reality, and logic is quite as incapable of shaking a man out of the one position as out of the other.

This I take it is the key to the agnosticism of such men of science as Mr. Huxley. I do not for a moment suppose that $\mathrm{Mr}$. Huxley believes less than most men: he probably has good grounds for believing a great deal more. Only he 
rightly refuses to say that he knoivs facts of which he can have had no direct apprebension and which he can only infer more or less probably, to be true. Hypotheses which as we push our investigations are shown to be capable of explaining more and more facts, that is, ultimately, more and more sensations, will in the end come to be believed in without doubt or hesitation. If a man says he knorils the law of gravitation to be trne, he commits a logical blunder ; but there is nothing to prevent a scientific man from believing in any miracle or prodigy, so long as the account he gives of it does not contradict itself. Not only may two equally reasonable men form very different estimates of the probability of the same event, even with the same evidence before them, but one man may put his faith to a proposition with admittedly much lower degree of probability than would be required to convince another. Only, a scientific man will always distinguish between what he knows and what he believes, and will admit that though he has made up his mind to act as if he knew to be true the propositions he only believes to be so, yet another man may reasonably take a different view of any one of them.

Trin. Coll., Cambridge, Jan. 8, I892.

Edward T. Dixon.

\section{COMTE AND TURGOT.}

On page 4 Io of the last number of The Monist, it was stated that the doctrine of the three stages of knowledge was not properly a Comtean idea but belonged to Turgot. The following letter from Professor Schaarschmidt of Bonn informs us of the passages in Turgot where the statement of the doctrine is found:

\section{To the Eiditor of The Monist:}

To your note of inquiry of the 22d of last month I have the honor to reply, that the Comtean theory of the trois elats may be traced back to utterances of Turgot made by him in his Second discours sur les progrès successifs de l'espril humain prononce le ame décembre 1750-namely in the Sorbonne. You will find the discourse referred to in the edition of the works of Turgot which I now have before me, namely that of Guillaumin, Paris, 1844 , in Vol. II, at pages 597 et seqq. The passage in question is found at p. 6oo-6or. However, it is highly probable that the so-called lii de's trois ćtuts was directly transmitted to Comte by St. Simon, who reproduced the idea of Turgot in his fitrviluction aux truvaux scientifinues du .$M$ 'Me Siécle, at pages 62-63. For Comte was dependent in many respects on St. Simon, while it is probable that he had never studied Turgot. To St. Simon, in fact, is due the expression "philosophie positive," as well as the germ-notion of the division of the Sciences, which Comte further elaborated.

SCHAARSCHMIDT. 